University of Nebraska - Lincoln

DigitalCommons@University of Nebraska - Lincoln

Faculty Publications, Department of Psychology

Psychology, Department of

November 2006

\title{
Does How I Feel About It Matter? The Role of Affect in Cognitive and Behavioral Reactions to an Illness Diagnosis
}

Darnell Schuettler

Northern Arizona University, dschuettler@hotmail.com

Marc T. Kiviniemi

University of Nebraska-Lincoln, mtk8@buffalo.edu

Follow this and additional works at: https://digitalcommons.unl.edu/psychfacpub

Part of the Psychiatry and Psychology Commons

Schuettler, Darnell and Kiviniemi, Marc T., "Does How I Feel About It Matter? The Role of Affect in Cognitive and Behavioral Reactions to an Illness Diagnosis" (2006). Faculty Publications, Department of Psychology. 63.

https://digitalcommons.unl.edu/psychfacpub/63

This Article is brought to you for free and open access by the Psychology, Department of at DigitalCommons@University of Nebraska - Lincoln. It has been accepted for inclusion in Faculty Publications, Department of Psychology by an authorized administrator of DigitalCommons@University of Nebraska - Lincoln. 
Published in Journal of Applied Social Psychology, 2006, 36, 11, pp. 2599-2618. Copyright @ 2006 by the Authors; Journal compilation @ 2006 Blackwell Publishing, Inc. "The definitive version is available at www.blackwell-synergy.com ."

\section{Does How I Feel About It Matter? The Role of Affect in Cognitive and Behavioral Reactions to an IIIness Diagnosis}

\author{
DARNELL SCHUETTLER \\ Northern Arizona University
}

MARK T. KIVINIEMI

University of Nebraska-Lincoln

Individuals often have low rates of compliance with treatment recommendations. We examined the role that experienced affect at the time of illness diagnosis might play in influencing thoughts and feelings relating treatment compliance. Participants were randomly assigned to receive a positive, neutral, or negative affect induction after imagining they were diagnosed with kidney cancer. They then reported on thoughts and feelings about the illness and the treatment regimen. Participants also reported interest in additional information about the illness and behavioral intentions for complying with the treatment regimen. Affect significantly influenced interest in information and behavioral intentions. Both effects were mediated by the influence of affect on participants' self-efficacy beliefs. These mediational findings support a mood-as-resource interpretation of the role of affect in treatment compliance.

Diseases such as heart disease, cancer, and diabetes are pressing public-health problems in the United States. Mortality from these three diseases collectively accounts for just over $50 \%$ of all deaths in the U.S. each year (Arias, Anderson, Kung, Murphy, \& Kochanek, 2003). Because of the public-health significance of morbidity and mortality from these diseases, there is a great deal of research focused on developing new and better ways to treat these illnesses.

Many of these treatments involve ongoing behavioral action on the part of the individual patient (e.g., compliance with pharmaceutical regimens, ongoing physical activity guidelines, changes in dietary intake). However, across a variety of treatments, people have remarkably low rates of adherence with the recommendations that they receive (World Health Organization, 2003). For example, at best, about $60 \%$ of heart-attack patients follow medication protocols 6 months after the incident (Butler et al., 2002; see also Burke \& Ockene, 2001; Sackett \& Snow, 1979).

${ }^{1}$ Correspondence concerning this article should be addressed to Darnell Schuettler, Northern Arizona University, South San Francisco Street, Flagstaff, AZ 86011. E-mail: dschuettler@hotmail.com
Because treatment strategies for many illnesses rely heavily on patient behaviors, given the evidence for low compliance with regimens, it is of great relevance to understand the factors involved in individuals' choices about complying with those treatment regimens. For many individuals, their first time considering and making choices about treatment-related behaviors comes when they receive an initial illness diagnosis from their physician. Understanding factors that influence how a patient reacts to the diagnosis and how those reactions relate to behavioral choices, therefore, may play a significant role in both understanding treatmentrelated behaviors and improving initial care for individuals diagnosed with serious illnesses.

\section{Affect and Reactions to Diagnoses}

Although a variety of factors may influence individuals' choices about behavioral options (Bowen, Helmes, \& Lease, 2001), an area that potentially may play a role is the individual's affective state at the time of diagnosis and initial consideration of treatment options. There are at least two reasons why the role of affect in response to an illness diagnosis may be important. First, being diagnosed with a serious illness often is associated (not surprisingly) with strong negative affect (e.g., Tedstone \& Tarrier, 2003), and individuals experience aversive emotional responses to even relatively mild information about risk for health problems (for a discussion, see Ditto \& Croyle, 1995). Documented negative affective reactions to serious illness include anxiety (Popkin, Callies, Lentz, Colon, \& Sutherland, 1988), depression (Epping-Jordan et al., 1999), and guilt (Taylor, Lichtman, \& Wood, 1984). Although such emotional reactions may occur at multiple points during the course of an illness, they often are particularly pronounced during the initial period after an illness diagnosis when one is coming to terms with the diagnosis and making decisions about how to respond (Moos, 1977).

Although the variety of negative emotional responses to diagnosis and their likely concentration at the initial stages of diagnosis and treatment initiation alone make examining their effects important, there are further reasons to expect emotions to have an important influence on illness responses. Affective responses have been shown to have significant influences on individuals' thoughts, decision making, and outcomes in a variety of areas, including decisions about health information (for reviews, see Aspinwall, 1998; Lowenstein \& Lerner, 2003).

How might affect influence a person's reactions to health diagnoses? There are a number of possible mechanisms by which affect might have an influence. Interestingly, across these mechanisms, one can find support for the notion that positive affect will lead to more adaptive responses to illness diagnoses (e.g., interest 
in learning more about the disorder and how to treat it, intention to follow a treatment regimen), but also can find strong support for the opposite prediction: that negative affect will lead to more adaptive responses.

In support of the idea that greater positive affect experienced when considering an illness diagnosis and treatment options is research demonstrating that positive affect is associated with increased interest in and attention to potentially threatening information about the self and health status. For example. Trope and Neter (1994) examined the role of affect on willingness to seek and accept negative feedback. Those in positive affective states show greater willingness to attend to negative information (see also Aspinwall \& Brunhart, 1996; Isen \& Patrick, 1983). In this perspective, positive affect serves as a resource allowing individuals the freedom to attend to threatening information. Thus, we might expect individuals in positive affective states to be more willing to attend to information related to a diagnosis of a serious illness and associated treatment options, and thus to be more likely to respond in adaptive ways to the diagnosis.

Not only has positive affect been shown to influence interest in and attention to information, it also has been shown to increase individuals' perceptions of their ability to deal successfully with potentially threatening situations. Both dispositional optimism and positive affect have been linked to higher self-efficacy beliefs in a variety of situations and stronger perceptions of response efficacy (Cozzarelli, 1993; Desharnais et al., 1990; Taylor et al., 1992). Given these findings, one might posit that positive affect could make adaptive responses to a serious illness diagnosis more likely by increasing perceptions of both self and response efficacy for following treatment regimens. Because self and response efficacy make engaging in a behavior more likely (Ajzen, 1985; Bandura, 1986), one might then expect that greater levels of positive affect following an illness diagnosis would be associated with more adaptive thoughts and behaviors related to the illness and to treatment options.

Although there are several lines of evidence that might lead one to hypothesize that individuals experiencing positive affect when receiving an illness diagnosis and considering treatment options would have more adaptive responses, there is also evidence to suggest that the opposite might be true. Other lines of work support the notion that negative affect might engender more adaptive responses to a potentially threatening situation.

One possibility is that negative affect at the time of diagnosis might influence perceptions of concern for the problem. In other domains, it has been shown that individuals can use affective associations to infer how risky a situation is or how concerned they should be (Bechara, Damasio, Tranel, \& Damasio, 1997; Lerner, Gonzalez, Small, \& Fischhoff, 2003). This notion is also the foundation for the use of fear arousal as a technique for motivating behavioral change: To the extent that fear is associated with a situation or health threat, individuals may be more motivated to take action to alleviate that threat (Leventhal, 1970). Thus, negative affect aroused by an illness diagnosis might influence both individuals' interpretation of their concern about the situation and their subsequent decisions about treatment options.

Second, some work has shown that, relative to individuals in a positive mood, individuals experiencing negative affective states are more likely to process information thoroughly and systematically (Kuykendall \& Keating, 1990; Worth \& Mackie, 1987). Thus, one might expect the degree of negative affect aroused when receiving a diagnosis and considering treatment options to increase the likelihood of fully processing information and to promote interest in additional information about the health problem and treatment options.

\section{Study Overview}

There are a variety of ways in which affective states might influence an individual's response to an illness diagnosis. Of particular interest is that the past literature has led to opposing predictions for the adaptive role of positive and negative affect in diagnosis. Given this and the potential importance of individuals' initial responses for coping with the illness and carrying out treatment regimens, the present study is designed to examine how individuals' affective states when considering treatment options will influence cognitive and behavioral responses to the diagnosis. Because past literature not only has generated opposing predictions for whether positive or negative affect will lead to more adaptive responses but also posits different pathways through which affect might influence outcomes (e.g., altering efficacy beliefs, changing perceptions of seriousness and concern), we also assess the relevant social cognitive constructs that the past literature suggests may be influenced by affect.

In order to examine these questions about the role of affect in response to a diagnosis of a serious health problem, we conducted a study in which participants were placed in a positive, negative, or neutral affective state after imagining having been informed of a diagnosis of a serious health problem. After the affect induction, we assessed several facets of participants' psychological response to the diagnosis and behavioral intention with regard to treatment options.

\section{Method}

Participants

The participants were 76 introductory psychology students from a large, midwestern university (65 female, 11 male; $M$ age $=20.1$ years). The students took 
part in the study in exchange for extra course credit. Participants were predominantly single $(90 \%)$ and Caucasian $(80 \%)$.

\section{Procedure}

Health-diagnosis scenario. Participants were told that the study concerns how people respond to health information, and their thoughts and feelings about that information. They were told that they would read a scenario about a health situation and would answer some questions about their response to the information.

First, participants received a written scenario about a visit to a doctor's office. They were asked to imagine that the events described in the scenario were actually occurring and that they were the patient in the scenario. In the scenario, participants were asked to imagine that they had not been feeling well. The scenario then described a visit to the doctor in which the doctor performed an examination and a series of laboratory tests, including special x-rays.

Following the tests, the doctor informed the patient that he or she had been diagnosed with renal cell cancer. The doctor then suggested that the patient undergo surgery to remove the cancerous area, as well as 6 to 7 weeks of radiation therapy either before or after the surgery. At this point, the patient was then presented with information about renal cell cancer. This information included a description of renal cell cancer and the variety of treatment options available. ${ }^{2}$

Affect induction. After completing the scenario task, participants were randomly assigned to receive either a positive, negative, or neutral affect induction. The appropriate affective state was induced using Velten's (1968) mood-induction procedure. As a cover story, participants were told that they were to complete a cognitive skills task. They were asked to read aloud a series of statements and to concentrate to the best of their ability on each statement.

Each participant read aloud a series of 30 statements. The positive affect induction included statements such as "I feel lighthearted" and "For the rest of the day, I bet things will go really well." The negative affect induction included statements such as "My life is so tiresome - the same old thing day after day depresses me" and "It seems that no matter how hard I try, things still go wrong." The neutral induction included statements such as "The mansion was rented by the delegation" and "Slang is a constantly changing part of the language."

Velten's (1968) mood-induction procedure has been used successfully in a variety of studies as a means of inducing particular affective states (Bartolic, Basso,

\footnotetext{
${ }^{2}$ The information that was presented was adapted from WebMD (2003).
}

Schefft, Glauser, \& Titanic-Schefft, 1999; Watkins, Teasdale, \& Williams, 2003; for a review, see Larsen \& Sinnett, 1991). Moreover, although some have questioned the transparency of the procedure (e.g., Kenealy, 1986), methodological work with the Velten technique has demonstrated that effects are not simply a result of demand characteristics (e.g., Berkowitz \& Troccoli, 1986; Finegan \& Seligman, 1995) and that the induction technique is a valid way of producing positive and negative mood states (Larsen \& Sinnett, 1991). During debriefing, no participants expressed suspicion about the procedure.

\section{Dependent Variables}

After completing the affect induction, participants were given a demographics sheet and a short, open-ended test of renal cell cancer knowledge. This test served as a filler task to decrease suspicion by allowing a time lag between the affect induction and the dependent variable measures. Next, participants completed a measure of current affect, which served as a manipulation check. ${ }^{3}$

Participants then completed a questionnaire containing measures of participants' motivation to overcome renal cell cancer, their self-appraisals, their beliefs about illness severity and impact, and their beliefs about engaging in potential treatments (see Measures). After completing the measures, participants were debriefed fully. Participants in the negative and neutral affect conditions also were given the opportunity to have a positive mood induced, although none took advantage of the offer.

\section{Measures}

Demographics and information check. Participants reported their gender, age, ethnicity, and marital status. ${ }^{4}$ The open-ended test section assessed participants' knowledge of the definition of renal cell cancer, recall of symptoms of renal cell cancer, number of stages of renal cell cancer, what stage the scenario described, and recall of the treatment suggested by the physician.

Manipulation-check affect measure. As a manipulation check, affective state was assessed using the Positive and Negative Affect Scale (PANAS; Watson, dark, \& Tellegen, 1988), a highly reliable measure of positive and negative affect (positive, $\alpha=.89$; negative, $\alpha=.92$ ). The PANAS consists of a list of 20 emo-

${ }^{3}$ Because repeated affect measures can sensitize participants to the measurement tool and thus change the nature of their responses, we chose not to assess pre-manipulation affect (see Campbell \& Stanley. 1966).

${ }^{4}$ Demographic characteristics did not influence any reported results. 
tional states (10 positive, e.g., "excited"; and 10 negative, e.g., "distressed").

For each emotional state, participants rated the extent to which they were currently experiencing the state. Ratings were made on a 5-point Likert-type scale ranging from 1 (very slightly or not at all) to 5 (extremely). The means of the positive and negative items served as measures of post-manipulation positive and negative affect.

Outcome variables. Items measuring decision-making constructs in the context of a serious illness diagnosis were developed and used to assess factors involved in decision making about the illness diagnosis and treatment options. ${ }^{5}$ Several constructs related to decision making for health behavior were assessed, as were two behavioral intention constructs: interest in acquiring additional information about the illness, and intention to follow the suggested treatment regimen.

To avoid the possibility of assessment of earlier constructs altering participants' assessment of subsequent constructs (for a discussion, see Schwarz, 1999; Schwarz \& Oyserman, 2001), items related to each construct were distributed randomly through the questionnaire. For each outcome construct, the mean of the individual items related to that construct was used to create a composite measure. All questions were answered using a 7-point scale ranging from 1 (very slightly or not at all) to 7 (extremely).

We assessed four constructs related to cognitions about the illness and treatment. The self-appraisals measure includes five items assessing individuals' perceptions of their ability to cope with cancer, to follow the treatment regimen successfully, and to overcome the illness (e.g., "How capable are you of following the treatment regimen?"; $\alpha=.90)$. The concern measure includes six items related to anxiety and concern about the illness, perceptions of illness severity, and concern about the proposed treatments (e.g., "How severe do you perceive your illness to be?"; $\alpha=.63$ ). The health-perceptions measure includes three items assessing the likelihood of being healthy following the cancer treatment (e.g., "How easy do you think it will be to return to a healthy state of life?"; $\alpha=.78$ ). Finally, the impact measure includes three items assessing how much of an impact the individual thinks the illness and treatment will have on daily life (e.g., "How much of an impact will this illness have on your life within the next year?"; $\alpha=.55)$.

${ }^{5}$ To our knowledge, there are no existing published measures for these constructs in the context of serious illness. Therefore, we developed items to measure these constructs. Although items were created a priori, we ran an exploratory factor analysis to examine whether our individual items covaried as expected, based on their division into constructs. The exploratory factor analysis confirmed the expected relations between individual items measuring a construct.
Finally, we measured two aspects of behavioral intention with regard to treatment for kidney cancer. First, the information interest measure includes two items related to interest in learning more about the illness and the treatment (e.g., "How interested are you in learning more about your illness?"; $\alpha=.93$ ). Second, the treatment behavioral intentions measure includes three items examining intention to follow the treatment regimen and intended effort to be exerted to follow the treatment and to overcome the illness (e.g., "How much effort are you going to put into following your treatment regimen?"; $\alpha=.93)$.

\section{Results}

\section{Overview of Analyses}

To examine how affect experienced when considering an illness diagnosis influences cognitive and affective reactions to treatment, we first examined how the affect manipulation influenced both interest in additional information about the illness and intention to follow treatment regimens. In addition, we examined the influence of affect on decision-making constructs that past literature has suggested might be influenced by affect (e.g., self-efficacy).

For each of these variables, we began by examining overall differences as a result of the manipulation using an omnibus ANOVA strategy. For variables where the overall ANOVA revealed significant between-group differences, we conducted follow-up tests using Fisher's least significant difference (LSD) test to examine the nature of these differences. ${ }^{6}$

\section{Affect Manipulation Check}

Prior to examining the relationship between mood and responses to cancer diagnosis and treatment recommendations, we first assessed whether our manipulation successfully induced the desired affective states in participants. Examination of the positive and negative affect scales shows that participants in the positive mood condition reported the highest positive $\operatorname{mood}(M=2.79, S D=0.77)$ and the lowest negative mood $(M=1.64, S D=0.71)$, followed by those in the neutral condition (positive $M=2.47, S D=0.72$; negative $M=1.96, S D=0.98$ ). Those

${ }^{6}$ Control of error rates is an issue of concern when conducting follow-up tests. However, when there are no more than three means to be compared, as long as the omnibus $F$ test in the ANOVA is significant, the error rate for the follow-up tests is held at the overall alpha value (for a discussion, see Howell, 1997). Because LSD provides the greatest statistical power for testing follow-up hypotheses with a significant omnibus test (Carmer \& Swanson, 1973), we elected to use it for our follow-up tests. 
in the negative mood condition showed the lowest positive $\operatorname{mood}(M=2.02, S D=$ $0.64)$ and the highest negative $\operatorname{mood}(M=2.26, S D=0.55)$ : positive mood, $F(2$, $73)=7.50, p<.01$; negative $\operatorname{mood}, F(2,73)=3.38, p<.05$. The mean effect size for the mood condition (positive or negative) versus control condition comparison in these data was $d=.44$. Interestingly, this effect size is nearly identical to the meta-analytic mean effect size for Velten's (1968) mood-induction studies using a cover story $(d=.46$; Larsen $\&$ Sinnett, 1991).

Follow-up analyses using Fisher's LSD (minimum $M$ difference $=0.40$ ) reveals that for the positive mood measure, those who completed the negative mood induction had significantly lower scores than did either the positive or the neutral groups ( $M$ differences $=0.78$ and 0.46 , respectively). The positive and neutral mood conditions did not differ significantly on the positive mood measure, although the means are in the right direction $(M$ difference $=0.32)$. For the negative mood measure, those in the negative mood induction condition had significantly higher negative moods than did those in the positive mood condition ( $M$ difference $=0.62$ ). The other two comparisons were not significantly different, although in all cases, the means were in the right direction (positive-neutral $M$ difference = 0.32 ; negative-neutral $M$ difference $=0.30$ ).

\section{Affect and Cognitive Beliefs Following Cancer Diagnosis}

Having established that the manipulation induced the desired patterns of affective states, we next turn to examining how affect influenced participants' thoughts, feelings, and intentions about the illness. Means by condition for each belief variable are summarized in Table 1 .

First, participants in the positive affect condition had higher self-appraisals $(\mathrm{M}=5.78, S D=0.80)$ than did participants in the negative affect condition $(M=$ $4.81, S D=1.30)$, whereas neutral condition participants fell in between the two $(M=5.69, S D=0.88), F(2,73)=6.86, p<.01$. Pairwise comparisons using LSD (with a minimum $M$ difference of 0.57 ) reveals that those experiencing negative affect tended to have lower self-appraisals than did either those experiencing positive affect $(M$ difference $=0.96)$ or neutral affect $(M$ difference $=0.88)$. However, the difference in self-appraisals between those in positive and neutral moods was not significant $(M$ difference $=0.08)$.

Next, participants in the positive affect condition demonstrated lower levels of concern about the diagnosis $(M=3.90, S D=0.66)$ than did participants in either the neutral or the negative condition (neutral, $M=4.37, S D=0.74$; negative, $M=$ 4.34, $S D=0.80), F(2,73)=3.39, p<.05$. Pairwise comparisons using LSD (with a minimum $M$ difference of 0.41 ) reveal that those in both the neutral and negative
Table 1

Cognitive and Behavioral Variables by Affect Condition

Positive affect $\underline{\text { Neutral affect }} \underline{\text { Negative affect }}$

\begin{tabular}{lcccccc} 
Variable & $M$ & $S D$ & $M$ & $S D$ & $M$ & $S D$ \\
\hline Cognitive variables & & & & & & \\
Self-appraisal & $5.78_{\mathrm{a}}$ & 0.80 & $5.69_{\mathrm{a}}$ & 0.88 & $4.81_{\mathrm{b}}$ & 1.31 \\
Concern & $3.90_{\mathrm{a}}$ & 0.66 & $4.37_{\mathrm{b}}$ & 0.74 & $4.34_{\mathrm{b}}$ & 0.80 \\
Health perceptions & $5.01_{\mathrm{a}}$ & 1.05 & $4.44_{\mathrm{b}}$ & 0.89 & $3.75_{\mathrm{c}}$ & 1.08 \\
Impact & $5.39_{\mathrm{a}}$ & 1.08 & $5.64_{\mathrm{a}}$ & 0.71 & $5.60_{\mathrm{a}}$ & 0.70 \\
Behavioral intentions & & & & & & \\
Information interest & $6.31_{\mathrm{a}} \mathrm{b}$ & 1.21 & $6.68_{\mathrm{a}}$ & 0.56 & $5.85_{\mathrm{b}}$ & 1.13 \\
Treatment intentions & $6.55_{\mathrm{a}}$ & 0.76 & $6.60_{\mathrm{a}}$ & 0.54 & $5.97_{\mathrm{b}}$ & 1.20 \\
\hline
\end{tabular}

Note. Different subscripts indicate significantly different means.

conditions were more concerned than were those in the positive condition (negative-positive difference $=0.44$; neutral-positive difference $=0.47$ ). However, there was no difference between those in negative moods and those in neutral moods $(M$ difference $=0.03$ ).

There also were significant effects of mood on health perceptions. Those in the positive condition displayed more positive health perceptions $(M=5.01, S D=$ $1.10)$, than did those in the neutral condition $(M=4.44, S D=0.89)$. Those in the negative condition displayed the worst health perceptions $(M=3.75, S D=1.10)$, $F(2,73)=9.98, p<.001$. Pairwise comparisons using LSD (with a minimum $M$ difference of 0.57 ) reveal that those with positive moods had higher health perceptions than did either those in neutral moods ( $M$ difference $=0.57$ ) or negative moods $(\mathrm{M}$ difference $=1.26)$. Those in neutral moods also had higher health perceptions than did those in negative moods $(M$ difference $=0.69)$.

The only exception to the strong role of affect in determining beliefs about illness was the measure of impact. There were no significant mean differences in the amount of perceived impact across the conditions (positive, $M=5.39, S D=1.10$; neutral, $M=5.64, S D=0.71$; negative, $M=5.60, S D=0.70), F(2,73)=0.61$, $n s$. Given that the omnibus $F$ test was not significant, no follow-up tests were conducted for impact. 


\section{Treatment Behavioral Intentions}

Next, we examined the role that the affect manipulation played in determining individual's behavioral intentions with regard to the diagnosis. For the measure of information interest, those in the positive mood condition reported greater interest than did those in the negative mood condition (positive, $M=6.31, S D=1.20$; negative, $M=5.85, S D=1.10)$. Interestingly, those in the neutral condition reported the greatest interest in additional information $(M=6.68, S D=0.56), F(2$, $73)=4.09, p<.05$. Pairwise comparisons using LSD (with a minimum $M$ difference of 0.57 ) reveal that there was no difference in information interest between positive and negative affect $(M$ difference $=0.46$ ), or between positive and neutral affect $(M$ difference $=0.37)$. However, those in neutral moods were more interested in additional information than were those in negative moods ( $M$ difference $=$ $0.83)$.

Finally, participants in the positive and neutral mood conditions displayed higher treatment-related behavioral intentions (positive, $M=6.55, S D=0.76$; neutral, $M=6.60, S D=0.54)$ than did those in the negative mood condition $(M=$ $5.97, S D=1.20), F(2,73)=3.75, p<.05$. Pairwise comparisons using LSD (with a minimum $M$ difference of 0.49 ) reveal that those in both positive and neutral moods showed no difference in their intentions $(M$ difference $=0.05)$, and that negative moods showed significantly lower intentions than did either positive $(M$ difference $=0.56)$ or neutral moods $(M$ difference $=0.62)$.

\section{Process Analysis: Why Does Affect Influence Behavioral Intentions?}

Having established the effects of the affect manipulation on each dependent variable, mediation analyses were conducted to examine whether the cognitive aspects of diagnosis response can account for the relations observed between affect and both information interest and treatment behavioral intentions. In other words, do cognitive response variables mediate the relations between affect and behavioral outcome variables?

Conceptually, analysis of mediation rests on four core criteria (Baron \& Kenny, 1986; Hoyle \& Robinson, 2004). First, the independent variable (affect) must be related to the dependent variable (information interest, behavioral intention). Second, the mediating variable (self-appraisal, concern, health perceptions) must relate to the dependent variable. Third, the independent variable must be related to the mediating variable. Finally, to conclude that an effect is mediated, the strength of the independent variable-dependent variable (IV-DV) must be attenuated when the mediated variable is included in the model.
We already have demonstrated the first and third criteria in the ANOVA analyses reported earlier. To test the second assumption - that the mediating variable is related to the dependent variable - we examined the correlations between each hypothesized mediator and the two dependent variables. Each of the hypothesized mediators was related to behavioral intention (self-appraisal, $r=.71$; concern, $r=$ -.23 ; health appraisal, $r=.39$; $p \mathrm{~s}<.05)$. For information interest, both selfappraisals $(r=.39)$ and health perceptions $(r=.23)$ were related significantly $(p<$ $.05)$. However, concern was not significantly related $(r=.19, n s)$.

Because our independent variable is a multilevel categorical variable, we used the ANCOVA strategy described by Hoyle and Robinson (2004) to test for the final mediational assumption. ANCOVA involves controlling for a variable (the covariate) prior to examining the relation between a categorical independent variable and a continuous dependent variable. Given this, we can test whether our hypothesized mediators actually reduce the strength of the IV-DV relation by comparing the strength of the relation in the ANOVAs reported earlier to the strength of the relation in an ANCOVA in which the hypothesized mediator is included as a covariate.

We first examined the extent to which each of the two plausible cognitive mediators predicted interest in additional information (because concern was not related to information interest in our analysis, it was not tested for mediation). We found that self-appraisals fully mediated the relation between affect and information interest. When self-appraisal was included in the model, the affect/information-interest relationship dropped to nonsignificant, $F(2,72)=1.93$, $n s$. Health perceptions attenuated the relation somewhat, but did not demonstrate evidence for full mediation, $F(2,72)=3.07, p<.05$. Without the hypothesized mediators in the model, the relation was as follows: $F(2,73)=4.09, p<.05$.

We then examined the three hypothesized mediators of the affect/ behavioralintention relationship. Here, too, self-appraisals mediated the relation, $F(2,72)=$ 1.07 , $n s$. Health perceptions also mediated the relation, $F(2,72)=1.89$, $n s$. Concern did not show any evidence of mediating the relation, $F(2,72)=3.22, p<.05$. Without the hypothesized mediators in the model, the relation was as follows: $F(2$, 73) $=3.07, p<.05$.

Because both self-appraisal and health perceptions appeared to mediate the relation between affect and behavioral intentions significantly, we further probed the nature of the interrelations between these variables. Examination of the selfappraisal/health-perception relation reveals that the two were strongly related $(r$ $=.71, p<.001)$. Given this strong relation, it is possible that both appear to be mediators because of their shared variance. To examine this possibility, we estimated a final ANCOVA model in which both self-appraisal and health perceptions were included as covariates in the model. In this analysis, where shared 
variance was controlled, only self-appraisal showed evidence of being a covariate: self-appraisal/behavioral-intention relation, $F(1,71)=50.03, p<.001$; healthperception/behavioral-intention relation, $F(1,71)=2.24$, $n s$, and with the covariates in the model, $F(2,71)=0.49, n s$.

\section{Discussion}

The present study was designed to examine the relationship between one's affective state and the thoughts, feelings, and behavioral intentions associated with a diagnosis of a serious health problem. Our results show that affect influenced individual's reactions to such a diagnosis. Compared to those in a negative mood, individuals who were in a positive mood experienced less anxiety about the illness, showed higher levels of perceived self-efficacy, had greater expectations for fully recovering from the illness, were more interested in additional information, and reported being more likely to follow the treatment regimens. Moreover, when we examined potential mediators of the affect/behavioral-intention relationship, we found that self-appraisal, expectations, and concern about the illness all were mediators through which affect influenced behavioral intention. Of the dependent variables we examined, only perceived impact of the illness was not influenced by the affect manipulation.

\section{Understanding Affect and Treatment Behaviors}

In particular, the mediational analyses in our study provide support for the mood-as-resource interpretation of affect's influence on treatment behaviors described in the introduction. Our mediational results reveal that the relation between affect and behavioral intention can be accounted for completely by a model in which beliefs about self-efficacy serve as a mediator of the affect/behavioralintention relation. In other words, the affect experienced at the time of the illness diagnosis influences self-perceptions of ability to successfully overcome the illness. In turn, those self-perceptions influence the likelihood that the newly diagnosed patient will form strong behavioral intentions to follow the treatment regimen and to overcome the illness.

Our main effects analyses demonstrate that, relative to those in a neutral mood, positive mood raised and negative mood lowered perceptions of self-efficacy. Thus, positive mood seems to serve as a self-related resource, providing buffering against the negative effects of the illness diagnosis, which in turn allows the individual to feel sufficiently efficacious to carry out treatment behaviors that increase the likelihood of a successful recovery from the health problem. By contrast, negative affect depletes resources, lowering perceptions of self-efficacy; thus, making compliance with treatment regimens less likely.
This finding is consistent with the perspective that positive mood serves as a psychological resource (e.g., Aspinwall, 1988; Isen, 2003). Under this perspective, positive affect provides self-enhancement. The positive self-related feelings engendered by self-enhancement, in turn, provide the individual the freedom to attend to potentially threatening information (e.g., Trope \& Neter, 1994) and to engage in necessary coping steps to respond to threats (e.g., Aspinwall \& Taylor, 1997).

In our findings, the positive-affect-condition participants were more likely to be interested in additional information about the threatening health problem and had stronger behavioral intentions to respond to the problem. Both of these effects were mediated by increased feelings of self-efficacy in the positive-affect condition. This provides evidence for the mood-as-resource perspective of positive affect. By contrast, our findings do not support a fear-appeals perspective on the influence of affect on behavioral responses. The fear-appeal perspective would posit that negative affect would be associated with more adaptive behavioral responses by increasing perceptions of health problem seriousness and need for concern. Although negative affect was associated with higher concern about the problem, that relation did not influence participant's behavioral intentions concerning treatment options.

\section{Limitations}

An obvious limitation of this study is that we used an imaginary scenario to simulate receiving a diagnosis of renal cell cancer. For a variety of reasons, the thoughts and feelings elicited by this technique are likely to be weaker than those that would occur in an actual medical diagnosis situation. The scenario technique did, however, allow us to manipulate mood experimentally. For the purpose of examining the role of affect in treatment decision making and the cognitive mechanisms through which affect has its influence, we believe that an experimental design is a critical need. There are simply too many potential third variables that might account for an affect/ behavioral-intention relation in a naturalistic setting. That said, with our experimental evidence for the causal role of affect in hand, follow-up studies examining the relation between affect at time of diagnosis and treatment behavioral decisions in naturalistic medical settings would provide strong corroborating evidence for our findings and evidence for its importance and generalizability.

Related to the first point, although our affect manipulation significantly influenced participants' moods (those in the positive-affect induction condition had 
the most positive and least negative moods, and so on), the overall differences in mood were relatively minor. Indeed, it might be best to characterize the moods induced by our experimental manipulation as mildly positive or negative. Although this may be a limitation in that the effect of the manipulation on mood is relatively small, two features are important to note. First, the effect size for the manipulated mood differences is consistent with other studies using procedures similar to ours with the Velten (1968) mood-induction technique (Larsen \& Sennett, 1991). Second, although the impact of our induction technique was small, that relatively small induced mood difference caused significant differences in the thoughts and feelings participants had about the illness, perceptions of their own capabilities for dealing with the illness, and intentions for gathering additional information and following treatment regimens. Given that the mood experienced in an actual illness diagnosis and treatment decision is almost certain to be much stronger than that induced by our manipulation, one would expect the effect of mood on decision making in the case of actual illness to be significantly stronger than that induced by our experimental procedure.

Another feature of our study to note is that we used generalized, nonspecific positive and negative affect inductions in our manipulations. Most studies in this area have used such manipulations. And the mood-as-resource hypothesis is based on generalized effects of positive affect. However, some theorists have argued recently that it may be important to examine how more specific emotions (e.g., anger or sadness, rather than simply negative affect) influence decision making (e.g., Ellsworth \& Smith, 1988;

Tiedens \& Linton, 2001). Given the evidence from these studies, it may prove fruitful to examine more specific emotions and their role in individual's reactions. This may be particularly important for illness diagnosis, because those diagnosed with a serious illness often report a multitude of negative emotions (e.g., both anger and sadness).

Finally, it may be important to consider differences in affective reactions across illnesses that might influence responses to our questions. Survey results show that Americans report being more frightened by thoughts of cancer than by other serious health problems (National Cancer Institute, 2004). Given this, negative affective reactions to cancer might be stronger than those to other related health problems, and the affective patterns associated with diagnosis might differ across health problems in ways that could influence individual's responses.

\section{Applied Implications}

The degree of positive affect experienced when considering reactions to an illness diagnosis and treatment options has a significant impact on individual's decision making. How might these findings inform healthcare practices? The results suggest that healthcare providers could aid adaptation and response to a serious illness diagnosis by increasing a patient's positive affect.

Although it is unrealistic to expect providers to use laboratory affect inductions in a clinical setting, there may be techniques that could be used to increase positive affect in such settings. First, the literature on reactions to illness diagnoses suggest that both increasing knowledge about the health problem and perceptions of control over the situation are associated with lower levels of anxiety and depression when diagnosed with a serious illness (Egbert, Battit, Welch, \& Bartlett, 1964; Spiegel, 1996). Educational programs that provide information and increase perceptions of control, therefore, might lead to affective states associated with more adaptive responses (Helgeson, Cohen, Schuiz, \& Yasko, 2001; Meyer \& Mark, 1995). Second, several studies of how providers' communication of information to patients influences patient reactions have shown that presenting information in a tone that conveys optimism about outcomes (within the bounds of reality) is associated with greater patient satisfaction and better adjustment to the illness diagnosis (for reviews, see Lamont \& Christakis, 2003; Silani \& Boraso, 1999). Use of such communication strategies might lead to more positive affective responses for patients and, therefore, to more adaptive responses to diagnosis and treatment options.

Positive and negative affect substantially influence reactions to diagnosis with a serious health problem. Individuals in positive moods are more likely to be interested in additional information about the illness and to report intentions to follow treatment recommendations to overcome the illness. Moreover, these effects are mediated by the extent to which the individual eels self-efficacy for the behaviors included in treatment. Because of the negative affect often associated with a serious illness diagnosis, understanding the role of affect in response to illness and in treatment decisions and the potential importance of positive affect for adaptive responses is important if individuals being diagnosed with serious illness are to respond and adapt effectively.

\section{References}

Ajzen, I. (1985). From intentions to actions: A theory of planned behavior. In J. Kuhl \& J. Beckmann (Eds.), Action control: From cognition to behavior (pp. 11-40). Berlin, Germany: Springer-Verlag.

Arias, E., Anderson, R. N., Kung, H. C., Murphy, S. L., \& Kochanek, K. D. (2003). Deaths: Final data for 2001. National Vital Statistics Reports, 52(3), 1-116. 
Aspinwall, L. G. (1998). Rethinking the role of positive affect in self-regulation. Motivation and Emotion, 22, 1-32.

Aspinwall, L. G., \& Brunhart, S. M. (1996). Distinguishing optimism from denial: Optimistic beliefs predict attention to health threats. Personality and Social Psychology Bulletin, 22, 993-1003.

Aspinwall, L. G., \& Taylor, S. E. (1997). A stitch in time: self-regulation and proactive coping. Psychological Bulletin, 121, 417-436.

Bandura, A. (1986). Social foundations of thought and action. New York: Prentice-Hall.

Baron, R. M., \& Kenny, D. A. (1986). The moderator-mediator distinction in social psychological research: Conceptual, strategic, and statistical considerations. Journal of Personality and Social Psychology, 51, 1173-1182.

Bartolic, E. I., Basso, M. R., Schefft, B. K., Glauser, T., \& Titanic-Schefft, M. (1999). Effects of experimentally induced emotional states on frontal lobe cognitive task performance. Neuropsychologia, 37, 677-683.

Bechara, A., Damasio, H., Tranel, D., \& Damasio, A. R. (1997). Deciding advantageously before knowing the advantageous strategy. Science, 275, 1293-1295.

Berkowitz, L., \& Troccoli, B. T. (1986). An examination of the assumptions in the demand characteristics thesis: With special reference to the Velten mood induction procedure. Motivation and Emotion, 10, 337-349.

Bowen, D. J., Helmes, A., \& Lease, E. (2001). Predicting compliance: How are we doing? In L. E. Burke \& I. S. Ockene (Eds.), Compliance in healthcare and research (pp. 25 41). Armonk, NY: Futura.

Burke, L. E., \& Ockene, I. S. (Eds.). (2001). Compliance in healthcare and research. Armonk, NY: Futura.

Butler, J., Arbogast, P. G., BeLue, R., Daugherty, J., Jain, M. K., \& Ray, W. A., et al. (2002). Outpatient adherence to beta-blocker therapy after acute myocardial infarction. Journal of the American College of Cardiologists, 40, 1589-1595.

Campbell, D. T., \& Stanley, J. C. (1966). Experimental and quasiexperimental designs for research. Chicago, IL: Rand-McNally.

Carmer, S. G., \& Swanson, M. R. (1973). An evaluation of ten multiple comparison procedures by Monte Carlo methods. Journal of the American Statistical Association, 68, 6674.

Cozzarelli, C. (1993). Personality and self-efficacy as predictors of coping with abortion. Journal of Personality and Social Psychology, 65, 1224-1236.

Desharnais, R., Godin, G., Jobin, J., Valois, P., \& Ross, A. (1990). Optimism and healthrelevant cognitions after a myocardial infarction. Psychological Reports, 67, 11311135 .
Ditto, P. H., \& Croyle, R. T. (1995). Understanding the impact of risk factor test results: Insights from a basic research program. In R. T. Croyle (Ed.), Psychosocial effects of screening for disease prevention and detection (pp. 144-181). New York: Oxford University Press.

Egbert, L. D., Battit, C. E., Welch, C. E., \& Bartlett, M. K. (1964). Reduction of postoperative pain by encouragement and instruction of patients. A study of doctor-patient rapport. New England Journal of Medicine, 270, 825-827.

Ellsworth, P. C., \& Smith, C. A. (1988). From appraisal to emotion: Differences among unpleasant feelings. Motivation and Emotion, 12,271-302.

Epping-Jordan, J. E., Compas, B. E., Osowiecki, D. M., Oppedisano, G., Gerhardt, C., \& Prine, K., et al. (1999). Psychological adjustment to breast cancer: Processes of emotional distress. Health Psychology, 18, 315-326.

Finegan, J. E., \& Seligman, C. (1995). In defense of the Velten mood induction procedure. Canadian Journal of Behavioural Science, 27,405-419.

Helgeson, V. S., Cohen, S., Schuiz, R., \& Yasko, J. (2001). Long-term effects of educational and peer discussion group interventions on adjustment to breast cancer. Health Psychology, 20, 387-392.

Howell, D. C. (1997). Statistical methods for psychology. (4 ${ }^{\text {th }}$ ed.). Belmont, CA: Duxbury.

Hoyle, R. H., \& Robinson, J. C. (2004). Mediated and moderated effects in social psychological research: Measurement, design, and analysis issues. In C. Sansone, C. C. Morf, \& A. T. Painter (Eds.), The Sage handbook of methods in social psychology (pp. 213233). Thousand Oaks, CA: Sage.

Isen, A. M. (2003). Positive affect as a source of human strength. In L. G. Aspinwall \& U. M. Staudinger (Eds.), A psychology of human strengths:

Fundamental questions and future directions for a positive psychology (pp. 179-195). Washington, DC: American Psychological Association.

Isen, A. M., \& Patrick, R. (1983). The effect of positive feelings on risk-taking: When the chips are down. Organizational Behavior and Human Performance, 31, 194-202.

Kenealy, P. M. (1986). The Velten mood induction procedure: A methodological review. Motivation and Emotion, 10, 315-337.

Kuykendall, D., \& Keating, J. P. (1990). Mood and persuasion: Evidence for the differential influence of positive and negative states. Psychology and Marketing, 7, 1-9.

Lament, E. B., \& Christakis, N. A. (2003). Complexities in prognostication in advanced cancer: "To help them live their lives the way they want to." Journal of the American Medical Association, 290, 98-104.

Larsen, R. J., \& Sinnett, L. M. (1991). Meta-analysis of experimental manipulations: Some factors affecting the Velten mood induction procedure. Personality and Social Psychology Bulletin, 17, 323-334. 
Lerner, J. S., Gonzalez, R. M., Small, D. A., \& Fischhoff, B. (2003). Effects of fear and anger on perceived risks of terrorism: A national field experiment. Psychological Science, $14,144-150$.

Leventhal, H. (1970). Findings and theory in the study of fear communications. In L. Berkowitz (Ed.), Advances in experimental social psychology (Vol. 5, pp. 120-186). New York, NY: Academic Press.

Lowenstein, G., \& Lemer, J. S. (2003). The role of affect in decision making. In R. J. Davidson, K. R. Scherer, \& H. H. Goldsmith (Eds.), Handbook of affective sciences (pp. 619-642). New York: Oxford University Press.

Meyer, T. J., \& Mark, M. M. (1995). Effects of psychosocial interventions with adult cancer patients. Health Psychology, 14, 101-108.

Moos, R. H. (1977). Coping with physical illness. New York, NY: Plenum.

National Cancer Institute. (2004). C-Change releases survey on cancer attitudes. NCI Cancer Bulletin, 7(10), 6.

Popkin, M. K., Callies, A. L., Lentz, R. D., Colon, E. A., \& Sutherland, D. E. (1988). Prevalence of major depression, simple phobia, and other psychiatric disorders in patients with longstanding Type I diabetes mellitus. Archives of General Psychiatry, 45, 64-68.

Sackett, D. L., \& Snow, J. C. (1979). The magnitude of compliance and noncompliance. In R. B. Haynes, D. W. Taylor, \& D. L. Sackett (Eds.), Compliance in health care (pp. 1122). Baltimore, MD: Johns Hopkins University Press.

Schwarz, N. (1999). Self-reports: How the questions shape the answers. American Psychologist, 54, 93-105.

Schwarz, N., \& Oyserman, D. (2001). Asking questions about behavior:

Cognition, communication, and questionnaire construction. American Journal of Evaluation, 22, 127-160.

Silani, V., \& Borasio, G. D. (1999). Honesty and hope: Announcement of diagnosis in ALS. Neurology, 53(Suppl.), S37-S39.

Spiegel, D. (1996). Cancer and depression. British Journal of Psychiatry, 168, 109-116.

Taylor, S. E., Kemeny, M. E., Aspinwall, L. G., Schneider, S. C., Rodriguez, R., \& Herbert, M. (1992). Optimism, coping, psychological distress, and high risk sexual behavior among men at risk for AIDS. Journal of Personality and Social Psychology, 63, 460473.

Taylor, S. E., Lichtman, R. R., \& Wood, J. V. (1984). Attributions, beliefs about control, and adjustment to breast cancer. Journal of Personality and Social Psychology, 46, 489-502.

Tedstone, J. E., \& Tarrier, N. (2003). Posttraumatic stress disorder following medical illness and treatment. Clinical Psychology Review, 23, 409-448.
Tiedens, L. Z., \& Linton, S. (2001). Judgment under emotional certainty and uncertainty: The effects of specific emotions on information processing. Journal of Personality and Social Psychology, 81, 973-988.

Trope, Y., \& Neter, E. (1994). Reconciling competing motives in self-evaluation: The role of self-control in feedback seeking. Journal of Personality and Social Psychology, 66, 646-657.

Velten, E., Jr. (1968). A laboratory task for induction of mood states. Behavior Research and Therapy, 6, 473-482.

Watkins, E., Teasdale, J. D., \& Williams, R. M. (2003). Contextual questions prevent mood primes from maintaining experimentally induced dysphoria. Cognition and Emotion, $17,455-475$.

Watson, D., dark, L. A., \& Tellegen, A. (1998). Development and validation of brief measures of positive and negative affect: The PANAS scales. Journal of Personality and Social Psychology, 54, 1063-1070.

WebMD. (2003). Kidney cancer (description and stage explanation). Retrieved August 18, 2003, from http://content.health.msn.com/content/healthwise/

World Health Organization. (2003). Adherence to long-term therapies: Evidence for action. Geneva, Switzerland: Author.

Worth, L. T., \& Mackie, D. M. (1987). Cognitive mediation of positive affect and persuasion. Social Cognition, 5, 76-94. 